\title{
Politicas públicas e capital social: Uma avaliação do RS Mais Igual
}

Public policies and social capital: An evaluation of RS Mais Igual

\author{
Ana Julia Bonzanini Bernardi \\ Jennifer Azambuja de Morais
}

\section{Resumo}

Este artigo procura conhecer os efeitos do programa RS Mais Igual sobre o capital social e os ideais de cidadania e inclusão da população beneficiada, através da análise de discurso nas entrevistas realizadas ao longo do projeto Observatório de Políticas Sociais do Estado do RS. Acredita-se que as consideraçóes dos beneficiários sobre os efeitos do programa, bem como a análise de aspectos imateriais presente no próprio discurso, sejam uma importante fonte para avaliação da efetividade desta política pública. A partir das análises de discurso, percebeu-se um incremento da autonomia e noçóes de cidadania por parte dos beneficiários, embora não tenha sido encontrado um maior engajamento em associaçóes cívicas.

\section{Palavras-chave}

Capital Social; Políticas Públicas; RS Mais Igual.

\section{Abstract}

This article investigates the major gains in terms of social, political, and cultural capital as well as ideals of citizenship and inclusion by the beneficiaries of RS Mais Igual through the analysis of discourse in the interviews carried out along the Observatory of Social Policies of the State of RS. It is believed that the beneficiaries' considerations about the effects of the program, as well as the analysis of immaterial aspects present in the speech itself, are an important source for evaluating the effectiveness of this public policy. In the discourse analyzes although a greater engagement in civic associations was not found, we perceived an increase on the feelings of autonomy and notions of citizenship by the beneficiaries.

\section{Keywords}

Social Capital; Public Policies; RS Mais Igual. 


\section{Introdução}

No cenário atual de crise política brasileira, passou-se a questionar o modelo de desenvolvimento social que está sendo aplicado ao longo dos últimos anos, sobretudo no que se dialoga entre políticas sociais e inclusão produtiva para eliminação da extrema pobreza no País. Desde a eleição de Luiz Inácio da Silva (Lula) em 2002, o País passou a adotar uma série de políticas sociais, que em formato de rede, articuladas principalmente a partir do Programa Brasil sem Miséria, sob a liderança do Bolsa Família, buscaram erradicar a extrema miséria vinculando programas de transferência de renda focalizados através de uma série de prérequisitos, afim de atingir as famílias mais necessitadas (POCHMANN, 2010; LAVINAS, 2007). Nesse sentido, sob mando do Ministério de Desenvolvimento Social, passaram-se a estabelecer uma série de acordos com os entes federados, buscando melhor atender as diferentes realidades do País.

Para além das açóes reconhecidas internacionalmente, como o Programa Bolsa Família e o Sistema Único de Assistência Social (SUAS), ampliou-se a gama de benefícios concedidos, bem como o gasto público com a área social. O lançamento do Plano Brasil sem Miséria, em junho de 2011, visou aprofundar os ganhos obtidos até então no Governo Lula atuando a partir de três principais eixos: 1) transferência de renda; 2) acesso a serviços públicos e 3) inclusão produtiva, com fins de garantir uma maior distribuição de renda.

As principais açóes do Plano Brasil sem Miséria incluem o Bolsa Família, o Benefício de Prestação Continuada da Assistência Social (BPC) e o Brasil Carinhoso, sendo direcionados aos brasileiros que tem renda familiar inferior a $\mathrm{R} \$ 70,00$ por pessoa, dando atençáo especial a grupos específicos que têm se mostrado mais propensos à situação da extrema pobreza, como comunidades tradicionais, indígenas, negros, crianças e mulheres. A inclusão destes para o recebimento do beneficio se dá via Cadastro Único e com o auxílio das equipes volantes que realizam busca ativa desta população, cerca de 687 mil novas famílias foram inclusas até o ano de 2013 (BRASIL, 2013).

A estratégia do Plano Brasil Sem Miséria buscava incluir os estados e municípios para facilitar a chegada aos beneficiários, de forma a moldar o programa conforme as necessidades locais. Dentro disso, para melhor operar no Rio Grande do Sul, foi firmado o Acordo de Cooperação 05/2011 entre o Ministério do Desenvolvimento Social (MDS) e o Governo do Estado do Rio Grande do Sul, colocando em prática o Programa RS Mais Igual com a finalidade de complementar a renda das famílias beneficiárias do programa Bolsa-Família (PBF) no plano estadual 
com um valor inicial de $\mathrm{R} \$ 50,00$ atendendo inicialmente cerca de 18,5 mil famílias (CEGOV, 2013).

O Programa RS Mais Igual ${ }^{1}$, que teve início em 2012, foca na complexidade das famílias gaúchas tanto a realidade de pobreza rural como a da urbana, ao também contemplar as particularidades de grupos minoritários, como indígenas, pescadores, quilombolas e catadores - possibilitando que estas diferentes famílias pudessem utilizar esta verba, conforme suas necessidades específicas. Desde então, segundo dados disponibilizados pela Casa Civil, das 436.585 famílias beneficiárias do Programa Bolsa Família no RS (totalizando um repasse mensal de R \$ 68.562.064,00 até agosto de 2014), o Programa RS Mais Igual atendeu mais de 100 mil famílias gaúchas. Para isso, o estado do Rio Grande do Sul investiu R \$5 milhóes em 2012, R\$27 milhôes em 2013 e R\$70 milhôes em 2014 (CEGOV, 2014). Conforme pronunciamento da Casa Civil, o RS Mais Igual em setembro de 2015 atendia cerca de 56 mil famílias, uma vez que a cada mês, cerca de 700 famílias deixam o programa, ou por superarem a linha da pobreza, ou por não terem mais filhos entre zero e seis anos, acumulando um desembolso mensal de cerca de $\mathrm{R} \$ 4,3$ milhôes por parte do Governo do Estado (RIO GRANDE DO SUL, 2015). Nesse sentido, tomando as políticas públicas como açôes de governo (PETERS, 1995; DYE, 1984) que são estruturadas para definir prioridades nos investimentos e gastos do estado, o RS Mais Igual se destaca como uma política pública de cunho social, ou especificamente uma política social focada na redução da pobreza.

Desta forma, visando analisar a efetividade do programa e procurar pontos de melhora, o Governo do Estado do Rio Grande do Sul, por meio da Casa Civil, estabeleceu-se uma parceria com o Centro de Estudos Internacionais sobre Governo (CEGOV) ligado à Universidade Federal do Rio Grande do Sul (UFRGS), para buscar compreender o perfil das famílias beneficiárias, bem como potenciais diferenças regionais e, sobretudo, a percepção dos beneficiários sobre os impactos do

\footnotetext{
${ }^{1}$ Em virtude de alteraçóes no plano nacional do PBF, com a edição do programa Brasil Carinhoso, visando manter o alinhamento das açóes pré-estabelecidas conjuntamente no Plano Brasil Sem Miséria e do Programa RS Mais Igual, foi renegociado a repactuação deste termo inicial, alterando-o o valor fixo inicial de $\mathrm{R} \$ 50,00$ para um valor variável, até que a família se emancipe da faixa de extrema pobreza, que no estado foi ratificada em $\mathrm{R} \$ 100,00$. Portanto, o critério de elegibilidade para o acesso ao beneficio, firmou-se na ocorrência de filhos de 0 a 6 anos, em famílias com renda per capita abaixo de $\mathrm{R} \$ 100,00$, após o recebimento de todos os benefícios do PBF e Brasil Carinhoso, valorizando entáo a primeira infância como critério de combate à extrema pobreza (CEGOV, 2014).
} 
programa na busca da superação da pobreza. O Observatório de Políticas Sociais do RS foi efetivamente implementado ao longo do ano de 2014, contando com uma rede de pesquisadores da UFRGS e a organização de 13 agentes de campo capacitados para coletar informaçôes através de questionários semiestruturados em nove regiôes do estado ${ }^{2}$, totalizando cerca de 281 entrevistas com os beneficiários.

Uma vez esclarecido o contexto geral do programa RS Mais Igual, bem como a metodologia utilizada pelo Observatório de Políticas Sociais para analisá-lo, este artigo tem o objetivo de investigar os efeitos desta política pública sobre o capital social e os ideais de cidadania da população beneficiada. Para alcançar este objetivo, serão analisados os relatos dos beneficiários, com o auxílio do software Nvivo. Acredita-se que as consideraçóes dos beneficiários sobre os efeitos do programa, assim como a análise de elementos imateriais presentes nos próprios discursos, caracterizemse como uma importante fonte para avaliação da efetividade desta política pública.

Dentro deste contexto, a metodologia deste trabalho busca analisar qualitativamente através dos discursos dos beneficiários possíveis impactos gerados pelo Programa RS Mais Igual no incremento da cidadania política e do capital social destes beneficiários, atentando a aspectos que possam melhorar políticas futuras no estado, visto que ao longo do ano de 2015 e 2016, com a troca de Governo sabe-se que os repasses foram diminuídos e que o programa se encontra em fase de desmonte ${ }^{3}$.

No que tange à metodologia qualitativa, Minayo (2008, p. 86) destaca duas principais correntes utilizadas na análise de políticas públicas. A primeira delas faz referência à escala de atitudes, que se baseia no uso de escalas para mensuraçáo de valores, opiniōes e vivências intersubjetivas por meio de atribuição numéricas (MINAYO, 2009, p. 85-86). Os problemas desta abordagem residem na

\footnotetext{
${ }^{2}$ Região Funcional 1 (Porto Alegre e Região Metropolitana), Região Funcional 2 (Vale do Taquari e Vale do Rio Pardo), Região Funcional 3 (Serra, Campos de Cima da Serra e Hortênsias), Região Funcional 5 (Sul), Região Funcional 6 (Campanha e Fronteira Oeste), Região Funcional 7 (Celeiro, Fronteira Noroeste, Missões e Noroeste Colonial), Região Funcional 8 (Alto Jacuí, Vale do Jaguari, Central e Jacuí Centro), Região Funcional 9 (Médio Alto Uruguai, Rio da Várzea, Norte, Nordeste, Produção e Alto da Serra do Botucaraí).

${ }^{3} \mathrm{O}$ diretor atual do Programa, Fabrício Renner, declarou em nota no site do programa que os repasses de benefícios foram paralisados em novembro de 2015 devido à insuficiência de recursos do Estado (CASA CIVIL, 2015). Em ligação ao Escritório do RS Mais Igual, no dia 20 de julho de 2016, obtivemos a informação de que atualmente os repasses seguem paralisados.
} 
homogeneização da amostra, uma vez que descarta as individualidades dos entes analisados mediante os critérios pré-estabelecidos pelo pesquisador.

Em contraponto, a segunda abordagem promove a construção dos indicadores qualitativos propriamente ditos, considerando-os como únicos a partir de cada realidade analisada, sendo esta o ponto de origem da construção dos indicadores. Desta maneira, os indicadores auxiliam na reprodução analítica da realidade de cada beneficiário e náo como uma forma de "comprovação" (MINAYO, 2009, p. 87). Nesse sentido, considerando-se os indicadores qualitativos como balizas avaliativas que permitem mapear com mais profundidade a natureza das mudanças ocorridas e em processo (DESLANDES, 2002), o uso da análise por narrativa permite uma maior compreensão dos aspectos intangíveis que se pretende analisar, os quais não seriam realizáveis por meio do método quantitativo.

Analisando os resultados obtidos no Observatório de Políticas Sociais do RS, aprofundados neste artigo, cabe não só o questionamento do modelo de políticas públicas a ser propagado, mas também do modelo de desenvolvimento humano que se busca implementar, visto o período político de instabilidade democrática e cortes de gastos nas áreas sociais. As reflexôes acerca da validade das políticas sociais realizadas neste último período se dão no sentindo de questionar a importância da inclusão cidadã destes que vivem às margens da sociedade, e até que ponto as políticas de transferência de renda conseguiram ultrapassar o limite da inclusão do consumo e, de fato, promoveram uma inclusão política destes cidadãos.

\section{Políticas públicas de redução da pobreza e a experiência de análise do RS Mais Igual}

O Observatório de Políticas Sociais do RS ${ }^{4}$ foi constituído em 2013 por uma equipe de onze pesquisadores, entre eles professores, doutorandos, mestrandos e graduandos da Universidade Federal do Rio Grande do Sul (UFRGS), além dos 13 agentes de campo e a equipe de apoio do RS Mais Igual. O projeto buscou investigar o perfil da pobreza nas diferentes regióes do estado, levando em conta os diferentes contextos nos quais as famílias estavam inseridas, assim como questôes de pertencimento a comunidades tradicionais, fatores étnicos e de gênero, balizando-se

\footnotetext{
4 Coordenação: Profa Dra Lígia Mori Madeira. Membros do Projeto: Dr ${ }^{a}$ Aline Hellman, Dr. Alexandre Ben Rodrigues, Me. Ana Julia Bonzanini Bernardi, Dra Daiana Hermann, Me. Leonardo Geliski, Profa Dra Letícia Maria Schabbach, Profa Dra Luciana Pazini Papi, Profa Dra Marília Patta Ramos, Taciana Barcellos Rosa, Thauana Serres e Profa Dra Vanessa Marx.
} 
com os três eixos de organização do Programa RS Mais Igual: 1) acesso à renda; 2) inserção produtiva e 3) acesso a serviços. Dentro deste objetivo, desenhou-se duas principais estratégias para o desenvolvimento do projeto, a primeira dizendo respeito ao estudo do perfil dos municípios e regiōes que participam do RS Mais Igual, uma vez que estas se diferem muito entre si. A segunda estratégia foi de traçar o perfil das famílias beneficiárias por meio dos questionários e entrevistas realizadas, para além dos dados quantitativos e características socioeconômicas, possibilitando a análise do impacto obtido pelo programa no combate à pobreza, observando aspectos simbólicos como capitais culturais, sociais e políticos trazidos na fala dos beneficiários.

Quanto ao primeiro objetivo, foi realizado uma pesquisa prévia, anterior ao processo de coleta de entrevista com os beneficiários, na qual buscou-se unificar as informaçóes socioeconômicas e de benefícios sociais de 496 municípios do Estado, utilizando diferentes fontes. Desta forma, foram inclusas informaçóes dos municípios que participam do RS Mais Igual, bem como daqueles que não aderiram ao programa, construindo um banco de dados que permitiu o mapeamento do perfil dos municípios participantes, possibilitando a comparação entre os mesmos.

A segunda dimensão da pesquisa incluiu a análise das entrevistas coletadas pelos agentes de campo, conduzidas por meio de questionário semiestruturado, contando com uma série de questôes fechadas que tratavam majoritariamente de dados socioeconômicos de cada família, tais como o perfil (rural, urbano, ou comunidades tradicionais), composição familiar e características de domicílio, dimensões da cidadania (posse de documentos e utilização de serviços públicos), sobre o acesso à educação e trabalho e característica de consumo e aquisição.

Nas questóes abertas, abordou-se o conhecimento dos beneficiários sobre os programas sociais em que estavam atrelados, além da forma de acesso a serviços públicos disponíveis na região. Buscou-se conhecer mais profundamente quem são e como pensam os favorecidos pelo programa, investigando como estes veem a pobreza, relacionam-se com ela, e enfrentam suas violências e as vulnerabilidades às quais estão expostos, além de compreender seu papel na política, movimentos sociais e exercício de direitos. Além disso, objetivou-se analisar os ganhos materiais e simbólicos das famílias, nos termos de maior autonomia, e aumento de poder de compra após o recebimento do benefício e também as suas expectativas acerca do futuro para si e para seus filhos, em comparação com a situação anterior. Do mesmo modo foram incluídas questôes amplas e subjetivas, para compreender se o respondente se "sentia 
feliz" e "seguro" ou se já havia passado por situação de discriminação (MADEIRA et al., 2015).

Para além das dificuldades mais costumeiras relatadas em projetos de avaliação e monitoramento de políticas sociais, o Observatório foi construído enquanto o RS Mais igual ainda estava sendo implementado, de forma que algumas famílias entrevistadas ainda não eram beneficiárias do programa ou haviam tido seu benefício descontinuado. Logo, foram necessárias adaptações e diferentes técnicas metodológicas para trabalhar com cada subgrupo dos entrevistados. Os agentes de campo selecionados não eram acadêmicos especializados no tema de políticas sociais, mas pessoas familiarizadas com a área em que deveriam atuar, cumprindo com a obrigatoriedade de ter curso superior completo, o que trouxe grandes benefícios no sentido de maior acesso aos beneficiários e em uma maior facilidade de acesso às localidades. Contudo, uma das maiores dificuldades relatadas foi localizar os beneficiários ou de convencê-los a participar das entrevistas, uma vez que estes temiam pelo corte do benefício.

Em termos gerais, muito foi construído e avaliado sobre o perfil dos beneficiários e os alcances do RS Mais Igual dentro dos limites prescritos pelo curto tempo de pesquisa. Os dados socioeconômicos levantados, bem como o perfil das famílias permitiu uma melhor compreensão das diferentes facetas da pobreza no estado, fornecendo um material sólido para o monitoramento e aperfeiçoamento do programa, ou a base para a fundação de outros. No que tange os ganhos em capital social, político e simbólico, além dos resultados gerais, serão analisados mais minunciosamente nos próximos itens. Mas analisando o panorama, sobre o trabalho desenvolvido, acredita-se que as suas limitaçóes estejam nas dificuldades inerentes ao processo de monitoramento e avaliação de políticas públicas, sobretudo no que tangem:

[...] as suas incapacidades de aferir aquisições materiais, mas especialmente simbólicas, no curto espaço de tempo em políticas cuja perspectiva e meta são a mudança de padróes de vida, aquisições de capitais, empoderamento e cidadania geracionais (MADEIRA et al. 2015, p. 108).

Nesse sentido, este trabalho enquadra-se na perspectiva cultural e institucional, no sentido de compreender a ação do estado na formação de capital social. Assim não excluindo nenhuma das duas vertentes, mas trabalhando a lógica de que o acúmulo de capital social propicia melhor desenvolvimento da sociedade e de 
que a gestão pública, junto com outros mecanismos, pode estimula, através das políticas públicas, o engajamento cívico, a confiança e a cooperação. Ou seja, a construção e fomento de capital social pode se dar através das políticas de fomento do estado, principalmente, as políticas de transferências de renda, pois essas são necessárias para que haja uma verdadeira emancipação da população desassistida de fato a realmente incluí-la no processo democrático como cidadáo, aumentando suas capacidades para além do âmbito da inclusão pelo consumo (D'ARAUJO, 2004; DEMO, 2003; NÉRI, 2001 e 2003; SEN, 2010).

\section{Capital Social}

O capital social é um conceito que trabalha com a importância da existência e da qualidade das relaçóes sociais para o desenvolvimento social, econômico e político de uma comunidade. Essas relações sociais são estabelecidas na forma de redes sociais ou de normas, e tammbém caracterizadas pelos atributos de reciprocidade, confiança, solidariedade e cooperação.

$\mathrm{Na}$ área da Ciência Política o conceito de capital social, tributário de teóricos clássicos, como Tocqueville, Durkheim e Weber, é debatido por Bourdieu (1980 e 1999), Coleman (1988 e 1994), Putnam (1996), Portes (1998), Fukuyama (2002), entre outros. No entanto, ganhou destaque com a obra de Putnam sobre a cultura cívica e o desenvolvimento regional da Itália. Trazendo para o debate a questáo de que sociedades são mais desenvolvidas quando possuem capital social, na medida em que "são práticas sociais, normas e relaçôes de confiança que existem entre cidadãos numa determinada sociedade, bem como, sistemas de participação e associação que estimulam a cooperação" (PUTNAM, 1996, p. 177).

Além das relaçóes de confiança e reciprocidade, Putnam ressalta que o capital social está ligado ao processo histórico e cultural, "o contexto social e a história condicionam profundamente o desempenho das instituiçôes" (PUTNAM, 1996, p. 191).

Altos níveis de capital social são positivos para a democracia, pois, segundo Putnam (1996), colaboram para participação cívica (reconhecimento e a busca do bem coletivo e público), igualdade política, solidariedade, confiança e tolerância, além da cooperaçáo mútua. Complementar a isso, Abramovay (2002) defende que a noçáo de capital social permite ver que os indivíduos não agem independentemente, assim, as estruturas sociais devem ser vistas como recursos, como um ativo de capital de que os indivíduos podem dispor. 
Entretanto, por mais que o conceito tente compreender as relaçóes e as estruturas sociais, observa-se um conjunto de críticas ao capital social e a sua aplicaçáo, principalmente quando relacionada com o estado. Críticos observam a postura elitista do conceito, que vislumbra no estudo de Putnam o bom desempenho institucional, e também o desenvolvimento regional relacionado às comunidades com acúmulo de capital social, caracterizando-se como um determinismo cultural. Entre os críticos é exercida a justificativa de que as comunidades não cívicas e sem volume de capital social estariam condenadas ao não desenvolvimento econômico e social.

A corrente neoinstitucionalista critica, principalmente, a ligação do contexto histórico para formação de capital social ou engajamento cívico. Evans (1996) articula a participação do Estado na criação de capital social, ou seja, o Estado pode promover a formação do capital social. Segundo Abu-El-Haj (1999, p. 96), Evans assume o pressuposto básico de que as "instituiçôes públicas, além de terem o monopólio da coerção, possuem a exclusividade da mobilização dos recursos sociais", determinando, em última instância o sucesso das iniciativas voluntaristas.

Especificamente no campo das políticas públicas na América Latina, o conceito de capital social vem ganhando destaque desde os meados da década de 1990. Sendo relacionado a um ideal neoliberal de políticas sociais, uma vez que foi incluso no receituário do Banco Mundial a partir de 1995, com a proposta de incluir outros setores além do Estado, na luta das melhorias sociais (HIGGINS, 2005). Dentro desta crítica, a abordagem de fomento do capital social buscava "desonerar" o Estado de uma participação tão forte na área social, uma vez que debate sobre a construção de relaçôes sociais entre os cidadãos como forma de organização social baseada em normas e redes de compromisso cívico de reciprocidade (associativismo), confiança e responsabilidade social, sendo fatores necessários para o empoderamento das comunidades pobres e construção de bens coletivos (KLIKSBERG, 2001; D'ARAUJO, 2003).

$\mathrm{Na}$ relação mais específica com políticas de redução de pobreza, Demo (2003) explica que não basta compreender os determinantes do acesso às oportunidades e o retorno de determinados ativos isolados (como a educaçáo), apresentados aos miseráveis, mas deve-se olhar de maneira abrangente para todo o contexto. Para o autor, nesse ponto entra o conceito de capital social, pois a capacidade de uma comunidade de se organizar frente a uma situação adversa é determinante de sua consequência de curto e de longo prazo. Esse processo passa não só pela mobilização 
interna da comunidade como pela sua capacidade de articulaçáo com outros níveis da sociedade através do voto, pressão política etc.

Nesse sentido, a construçáo de altos níveis de capital social potencializa uma maior ação democrática e defesa de princípios de igualdade, garantindo que os investimentos sociais se tornem permanentes e crescentes. A seguir analisaremos algumas das entrevistas realizadas pelos beneficiários, buscando evidenciar possíveis mudanças em termos de capital social, reconhecimento e acesso à cidadania, gerados pelo programa.

\section{Análise do impacto do RS Mais Igual na formação de cidadãos - empoderamento, cidadania e acesso a direitos}

Através das análises realizadas na pesquisa podemos observar que as famílias entrevistadas tinham grandes carências em outras formas de capitais, para além do capital econômico, sobretudo no que tange a dimensão de capital social. As análises qualitativas e definição do perfil das famílias beneficiadas deixaram claro os ganhos em termos de melhorias da qualidade de vida e ampliaçáo das capacidades, sejam de consumo, ou da própria melhora da autoestima e conhecimento da utilizaçáo de serviços públicos disponíveis.

Embora as carências ainda existam, uma vez após o acesso ao benefício verifica-se possibilidades de melhora no futuro destas famílias, uma vez que o acesso ao benefício está atrelado a condiçôes como frequência escolar dos filhos na escola, acompanhamento médico das crianças e uma maior inclusão dentro dos benefícios públicos previstos pelo Estado. Especificamente, percebeu-se um maior empoderamento das mulheres (apenas houve um homem entrevistado), que como chefe de casas, tendo acesso ao valor, sentiam-se mais seguras e "donas de si", quando questionadas como se sentiam em relação ao recebimento do benefício. Dentro da amostra de 370 entrevistas, apenas 4 foram realizadas com homens. Ao questionarmos aos entrevistados quem era responsável pela administração do cartão verificamos que $98 \%$ das vezes são as próprias mulheres entrevistadas, conforme demonstrado no Gráfico 1 abaixo. 
Gráfico 1 - Responsável pela administração dos benefícios (\% de mulheres)

Fonte: CEGOV, 2014.

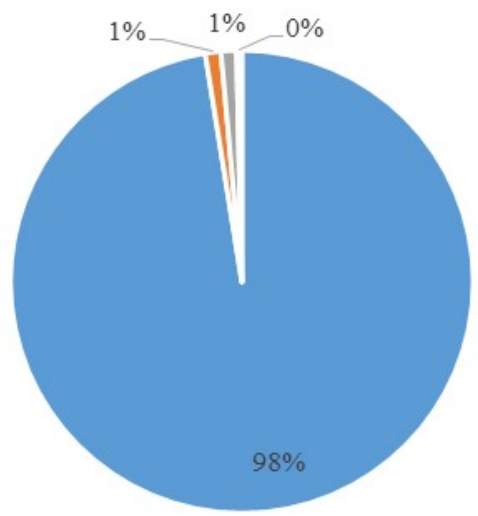

- A(o) própria(o) entrevistada(o)

- Filha da(o) entrevistada(o)

- A(o) entrevistada(o) e o cônjuge

" Toda a família $\mathrm{n}=276$

Quando questionadas se o recebimento do benefício, fazia com que estas mulheres se sentissem mais autônomas, grande parte (cerca de 79\%) respondeu que sim, conforme demonstrado no gráfico abaixo.

Gráfico 2 - Você se sente autônoma? (\% de mulheres)

Fonte: CEGOV, 2014.

$\mathrm{n}=366$

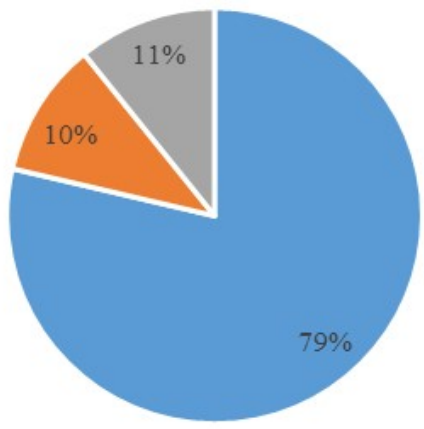


Neste mesmo sentido, ao analisar os relatos das beneficiárias, é recorrente não só a afirmação do maior sentimento de autonomia, como também fica implícita, e em algumas declaraçôes de forma mais explícita, a relação entre o aumento de autonomia trazido pelo benefício e o acréscimo de sua própria autoestima e sentimento de cidadania. Ao analisar o Gráfico 3, por exemplo, pode-se observar que $81,4 \%$ dos beneficiários indicaram que antes do recebimento do beneficio não era possível a compra de artigos que fossem além da cesta básica.

Gráfico 3 - Antes do benefício, sobrava dinheiro para comprar roupas, calçados e artigos de necessidade pessoal? (\% de respondentes)

Fonte: CEGOV, 2014.

$\mathrm{n}=370$

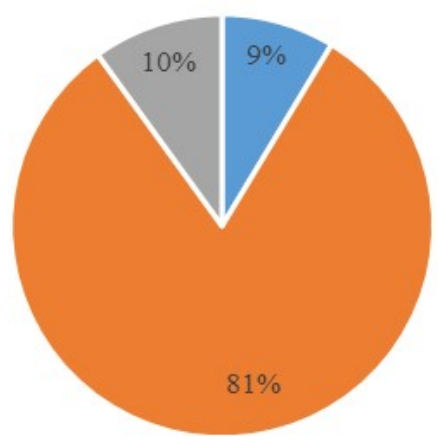

O mesmo também fica explicito nos relatos dos beneficiários, que indicam maior autonomia na decisão do que será consumido após o recebimento dos benefícios.

"Pois é... eu me sinto bem porque aí tu pode favorece o teu filho. Um tênis melhorzinho, né? A roupa, uma coisa que eles queiram, né? Não... as vez não pode dá e com o Bolsa tu tem aquele... todo mês aquele dinheirinho ali que tu pode usa, eu vo dá, vou consegui te da isso, vou consegui te da aquilo. Como eles pedem, né? Esse de quinze e a de oi... a de cinco já pedem. Que marca quer, que tipo quer. Aí tu consegue, né? [...]... bah eu me sinto bem porque, tem coisa as vez assim, né, que tu precisa mesmo ah, esse mês vo compra isso, sabe, deixo isso que eu preciso menos pro outro mês" (Bagé, entrevista 5). 
"É, esse cartão pra mim foi muito bom, tipo assim. Tu sentir um orgulho de ter um dinheiro, uma coisa pra poder manter a tua família, né? E, no caso, sou eu que recebo, né, e compro as coisas. Eu que administro, né?" (Porto Alegre, entrevista 5).

A posse do cartão e a decisão de como utilizá-lo aumentou o sentimento de cidadão, possuidor de direitos, conforme relatado por grande parte dos beneficiários nas entrevistas. Embora se mostre recorrente a dificuldade no acesso a estes serviços básicos, os beneficiários sentem-se em posse de direitos, e indicam que a integração ao programa possibilitou uma maior familiaridade com os serviços públicos disponíveis, conforme pode ser observado nos relatos abaixo:

"Sim, eu acho que como todos nós, no caso né, a população tem que se sentir assim. (...). É, não é muito fácil, né. A gente tem que corre bastante atrás, muitas vezes a gente leva um não, que não tem, mas eu corro atrás quando eu preciso alguma coisa. Nem sempre a gente consegue, né, mas...” (Bagé, entrevista 3).

"Se eu procura eu vô encontra, né. Eu sei que eles existem" (Santa Maria, entrevista 12).

"olha, eu acho que todo mundo tem direito a tudo, né, só não tem se não quer, se tu não correr atrás, se eu ficar aqui sentada eu não vou conseguir, se eu for atrás e for a luta, com certeza, que nem o Bolsa Família, eu fui la e fiz, demorou, demorou de fato, demorou mas veio né, então é um direito meu, um direito da minha filha, que se eu tivesse deixado eu não teria hoje, e hoje eu tenho posso usufruir dele porque eu fui atrás, que nem o colégio, a mesma coisa, que nem tudo na vida da gente é assim né?" (Santana do Livramento, entrevista 2).

Outra dimensão demarcada pelos beneficiários foi o entendimento que junto com os direitos, também haviam deveres a serem cumpridos, demonstrando uma boa compreensão dos ideais do programa dentro do objetivo de prover uma vida melhor à família como um todo, e especialmente às crianças. Grande parte dos relatos referem que o valor mensal é investido quase que completamente em prol dos filhos, seja em alimentação, material escolar ou vestimenta. A entrevistada 12A de Porto Alegre, quando perguntada se sente possuidora de direitos, destaca: 
"Eu... Claro que eu me considero uma pessoa... Eu me sinto, sim, uma pessoa que tem esse direito. E eu considero que, para minha classe social, esse direito ele é quase que inexistente, né, de certa forma. Ele até existe, mas é aquela coisa assim: é pouco, é muito pouco. Mas também tem aquela coisa: as pessoas... Não adianta também ficar só buscando direito, direito, direito e não cumprir com as minhas obrigaçôes, né? Então, tudo é uma coisa que eu tenho que pesar. Eu tenho, meus direitos tão ali. Vai ter pessoas que váo querer passar por cima dos meus direitos, mas assim também como vão ter pessoas que vão deixar usufruir dos meus direitos. Mas eu também não posso esquecer das minhas obrigaçóes, né?" (Porto Alegre, entrevista 12A).

Nesse sentido, podemos relacionar a autonomia e o maior conhecimento dos seus direitos como uma alavanca para uma maior inclusão cidadá, que inclui um maior conhecimento dos direitos e deveres cívicos, impulsionando maior interesse na esfera política para buscar garanti-los. Dentro disso, perguntou-se para os beneficiários, qual era seu papel nas escolhas políticas e de que forma estas poderiam participar, cobrar e influir na vida pública. Percebe-se uma certa impotência no discurso das beneficiárias, que veem a esfera política como distante de si, e um grande descrédito do sistema político em geral. Em muitos relatos, observa-se a participação política como algo meramente relacionado à arena eleitoral. Segue alguns destacados abaixo:

"Olha pra te falar a verdade no ano passado, o outro, na última eleição eu nem votei porque vieram aqui, ali na rua, vieram aqui arrumar a rua, botaram todo o barro aqui, não tinha passada, eu tive que fazer aquela passada ali, bota pedra. Que eles vem, em vez deles melhorar eles pioram, então não adianta. A luz mesmo eu pago iluminação pública mas tu vem aqui de noite tu não enxerga nada. Que não tem (...) Ai, eu vou, eu cobro, eu peço mas não adianta, né. Entáo, vota pra que se tu vota e não te ajudam em nada. Eu acho, pelo menos a mim não me ajudam" (Dom Pedrito, entrevista 6).

"Tu sabe que eu vejo bem... em quem vota, tu ta dizendo? Tu sabe que eu me decepcionei bastante com alguns que eu votei e já teve anos que eu votei em branco mas aí eu vi que em branco não valia a pena aí eu votei naquelas pessoas que, bom acho que esse aí pode (...)Eu acho que o... meu papel é como cidadã mesmo, né? Como eu tava te falando porque se tu paga tanto imposto e só porque tu é pobre ah... aparente mente vão te tratar mal, se fosse..." (Bagé, entrevista 2). 


\begin{abstract}
"Não... eu já estou muito desanimada com estas coisa, e eu ai eu penso assim se eu fosse fazer o meu papel certo de repente, mas só que... como eu pode ter muitas outras pessoas que falam a mesma coisa que vão lá e votam em branco, e ai a gente sempre vai deixando os pior, sempre deixando os pior eles podem dizer assim que tu é um só mas ai do outro lado tem outro também, mais uma mais um e assim...” (Encantado, entrevista 1).
\end{abstract}

Em contraste, outras beneficiárias, apesar de desacreditadas da política, afirmam que é importante cobrar dos políticos suas promessas eleitorais, mostrando, mais uma vez, a temática da percepção dos seus direitos. Porém, como fica claro nos relatos, muitas não sabem como fazê-lo de forma prática.

"O meu papel eu acho que é, tipo, brigar pelos meus direitos e direitos das outras pessoas também, né? Pra gente ter, poder conviver num mundo melhor, ter as coisas direitinho, ter... Como é que eu vou te dizer? Acesso livre a muitas coisas que a gente precisa, né, pra sobreviver... Porque eu acho que a gente já vota pra, pra ter um... Como é que eu vou te dizer? Uma resposta daquilo ali, né? Tu tá votando na pessoa pra pessoa fazer melhorias, tentar fazer pelo povo, né? Acho que é isso" (Porto Alegre, entrevista 5B).

"Acho que o povo se acomoda um pouco né tinha que cobra um pouco mais" (Palmeira das Missóes, entrevista 19).

Outra beneficiária de Alvorada, conforme relato abaixo, demarca o reconhecimento dos direitos e da necessidade de cobrá-los, porém pontua a dificuldade de organizar a comunidade para fazê-lo, com medo de que frente a uma mobilização com maior número de pessoas venha a envolver ação policial e mesmo violência, frente a percepção de uma "bagunça":

No caso, assim: a gente sabe que a gente tem direito, né? Mas e ir lá cobrar daí, entendeu? Se não for muita gente... Se for uma pessoa só, eu acho que tem uma... Não vai ter uma aceitação; e se for muita gente lá cobrando ao mesmo tempo, vai ter... Bagunça. (riso) capaz até de ter... De envolver até a polícia, né? De tomar outros rumos, né? (Alvorada, entrevista 3B).

Quando questionadas sobre a participaçáo em movimentos sociais, organizaçóes não governamentais, associaçôes comunitárias, ou até mesmo projetos 
do governo em sua região, observaram-se pouquíssimas respostas positivas, conforme demonstrado na tabela abaixo. Conforme consta no Gráfico 4, apenas $13 \%$, de um total de 370 entrevistadas mencionou participar de algum movimento ou instituiçáo social.

Gráfico 4 - Participa de algum movimento ou instituição social? (\% de respondentes)

Fonte: CEGOV, 2014.

$\mathrm{n}=370$

$$
\text { - Sim " Não " Não respondeu }
$$

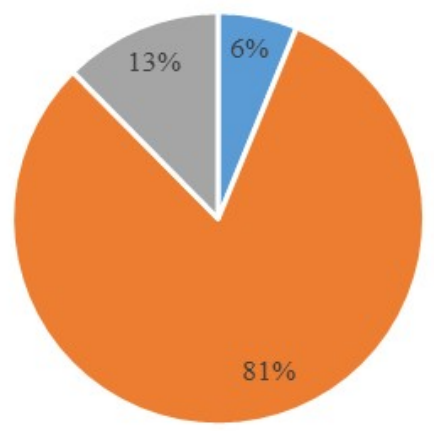

Dentro das poucas respostas positivas, encontramos beneficiários que citaram terem participado do Orçamento Participativo, e também atividades de associaçóes comunitárias em Porto Alegre. Algumas das referências encontradas dizem respeito as entidades religiosas, de forma que as associaçóes de cunho político foram, realmente, muito pouco mencionadas.

Conforme pode ser analisado, não há um grande engajamento em associações cívicas ou um aprofundamento dos laços de capital social a partir da introdução do programa. No entanto, percebe-se um aumento da autonomia e noçóes de cidadania e cooperação horizontal dos beneficiários, o que sugere, que houve sim, um incremento nas percepçóes de cidadania e direitos a partir do programa.

\section{Considerações finais}

O avanço das políticas públicas de desenvolvimento social no Brasil nos últimos anos do Governo PT, ao passo que possibilitaram a retirada de uma grande parcela da população da miséria (POCHMANN, 2010; LAVINAS, 2007), atendendo suas necessidades básicas, deram-se, sobretudo, na esfera da inclusão pelo 
consumo, não permitindo a formação de um maior capital social e, por conseguinte, uma maior emancipação e sociabilização política (PASE e SANTOS, 2011). Embora as políticas de transferência de renda tenham certos limites quanto à geração de capital social e político, é necessário refletir que no caso brasileiro, dadas às inúmeras fragilidades e vulnerabilidades da população desassistida "dar o peixe, é condição necessária para se aprender a pescar” (NERI, 2003, p. 75). Desta forma, a continuidade de projetos como o RS Mais Igual se mostra necessário para a manutenção do projeto de erradicação da miséria e redução das desigualdades no Brasil.

A análise do RS Mais Igual demonstra que embora o programa tenha proporcionado uma grande melhoria na qualidade de vida da população em termos de retirada de situação da miséria extrema, seu efeito em termos de formação de capital social e político, não teve o mesmo alcance desejado, muito embora tenha proporcionado um grande passo para a efetivação destes no longo prazo, através do empoderamento feminino e do aumento da autonomia e formação de capacidades das beneficiárias. Acredita-se que o desenvolvimento pleno em termos de capital social e político foram limitados devido às condiçóes iniciais destes beneficiários, que se encontravam em grande parte em situaçóes de grande vulnerabilidade, para que em tấo curto tempo fosse possível observar uma modificação nos seus padrôes de participação política efetiva e de capital social. Contudo, o recebimento do benefício se mostra importantíssimo para o planejamento familiar e, portanto, eleva as perspectivas de um futuro sem miséria para novas geraçôes de cada família.

Além disso, o problema da desigualdade no país náo é passível de solução apenas por meio de intervençóes sociais pontuais, pois carece, sobretudo, de uma reforma do sistema tributário e político. O crescimento econômico recente no Brasil foi responsável pelo enriquecimento das velhas elites econômicas, políticas e administrativas do país não beneficiando completamente os grupos mais pobres (MIDGLEY, 1995, p. 130). Desta forma, pode-se dizer que estas políticas sociais não tiveram um caráter redistributivo da riqueza do país, mas sim compensatório, não modificando a estrutura de poder das elites - que continuaram a ser as principais beneficiadas dentro do jogo político. Desta forma, o desequilíbrio entre diminuição dos ganhos reais destas políticas sociais frente a desestabilidade econômica, náo apenas aumentou a insatisfação com o governo atual, como também diminuiu o capital social da população e incidiu sobre uma maior desconfiança das Instituiçôes, e 
partidos políticos, principalmente sob o signo da corrupçáo generalizada (BAQUERO, 2015).

A fins de conclusão, apontamos que os avanços obtidos em matéria de capital social e político através do RS Mais Igual foram restritos ao sentido de maior empoderamento e sentimento de inclusão cidadã - sobretudo dentro da ótica de sentir-se mais autônomo e merecedor de direitos. Entretanto, no que tange a confiança no sistema político, associativismo e participação não foram registrados dados que possibilitassem afirmar que houve um avanço nesses termos.

Ana Julia Bonzanini Bernardi é Doutoranda em Ciência Política da Universidade Federal do Rio Grande do Sul (UFRGS). E-mail: anajuliabbernardi@hotmail.com.

- Jennifer Azambuja de Morais é Doutora em Ciência Política pela UFRGS e Pós-Doutoranda em Ciência Politica pela UFRGS. E-mail: jennifer.amorais@gmail.com.

\section{Referências}

ABU-EL-HAJ, Jawdah. A mobilizaçấo do capital social no Brasil: O caso da reforma sanitária no Ceará. São Paulo: Editora Annablume, 1999.

ABRAMOVAY, Miriam. Juventude, violência e vulnerabilidade social na América Latina: desafios para as políticas públicas. Brasilia: Unesco; BID, 2002.

BAQUERO, Marcello. A dimensão oculta da democracia latino-americana: A inércia e formas para superá-la. 122f. Tese para promoção à Professor Titular - Instituto de Filosofia e Ciências Humanas, Programa de Ciência Política, Universidade Federal do Rio Grande do Sul, Porto Alegre, 2015. No prelo.

BRASIL. Ministério do Desenvolvimento Social e Combate a Fome. Desenvolvimento social e combate à fome no Brasil: balanços e desafios. Brasília, DF: MDS, 2010.

BRASIL. MDS. Plano Brasil Sem Miséria no seu Município. 2003. Disponível em: <http://www.brasilsemmiseria.gov.br/documentos/cartilha-encontro-prefeitos-final-

18022013.pdf>. Acesso em: 12 fev. 2016>.

BOURDIEU, Pierre. Le Capital Social: Notes Provisoires. Actes de la Recherche en Sciences Sociales, n. 31, p. 2-3, 1980. Disponível em: <http://www.persee.fr/web/revues/home/prescript/ article/arss_0335_5322_1980_num_31_1_2069>. Acesso: 12 fev. 2016.

CEGOV. Projeto do Observatório de Políticas Sociais do Estado do RS. Coord. Ligia Mori Madeira. Porto Alegre: UFRGS, 2013. 
. Primeiro Relatório do Observatório de Políticas Sociais do Estado do RS. Coord. Ligia Mori Madeira. Porto Alegre: UFRGS, 2013.

- Relatório Técnico Parcial: Síntese dos Resultados obtidos I. Coord. Ligia Mori Madeira.

Porto Alegre: UFRGS, 2013.

. Síntese dos Resultados II. Coord. Lígia Mori Madeira. Porto Alegre: UFRGS, 2013.

. Relatório Final do Observatório de Políticas Sociais do Estado do RS. Coord. Ligia Mori

Madeira. Porto Alegre: UFRGS, 2013.

- Banco de Dados do Projeto Observatório de Políticas Sociais do Estado do RS. Coord. Ligia

Mori Madeira. Porto Alegre: UFRGS, 2013.

COLEMAN, James. Social Capital in the Creation of Human Capital. Supplement: Organizations and Institutions: Sociological and Economic Approaches to the Analysis of Social Structure, 1988. p. S95-S120.

D’ ARAUJO, Maria Celina. Capital social. Rio de Janeiro: Jorge Zahar. 2003.

DEMO, Pedro. Pobreza da pobreza. Rio de Janeiro: Editora Vozes. 2003.

DESLANDES, Suely Ferreira; ASSIS, Simone Gonçalves. Abordagem quantitativa e qualitativa em saúde: o diálogo das diferenças. In: MINAYO, Maria Celia de Souza; DESLANDES, Suely Ferreira (Orgs.). Caminhos do Pensamento. Epistemologia e Método. Rio de Janeiro: Ed. Fiocruz, 2002, p.195-226.

DYE, Thomas D. Understanding Public Policy. Englewood Cliffs, N.J.: Prentice- Hall. 1984.

FARIA, Carlos Aurélio Pimenta. A política de avaliação das políticas públicas. Revista Brasileira de Ciências Sociais, São Paulo, v. 20, n. 59, p. 97-169, 2005.

FUKUYAMA, Francis. Capital Social. In: HARRISON, Lawrence; HUNTINGTON, Samuel (Orgs.). A cultura importa. Rio de Janeiro: Record, 2002, p. 155-171.

HIGGINS, Silvio Salej. Fundamentos Teóricos do Capital Social. Chapecó: Argos Ed. Universitária, 2005.

KLIKSBERG, Bernardo. El rol de capital social e de la cultura en el proceso de desarrollo. In: KLIKSBERG, Bernardo; TOMASSINI, Luciano (Comp.). Capital social y cultura: claves estratégicas para el desarrollo. Buenos Aires: BID, Fondo de Cultura Económica de Argentina, 2000, p. $19-58$.

LAVINAS, Lena. Gasto social no Brasil: programas de transferência de renda versus investimento social. Ciência \& Saúde Coletiva, Rio de Janeiro, v. 12, n. 6, p. 1463-1476, dez. 2007.

MADEIRA, Ligia Mori; PAPI, Luciana Pazini; MARX, Vanessa; CARVALHO, Paola Loureiro; SCHABBACH, Letícia Maria; RAMOS, Marília Patta; HERMANN, Daiana. BERNARDI, Ana Julia Bonzanini; RODRIGUES, Alexandre Bem; GELISKI, Leonardo; ROSA, Taciana Barcelos; SERRES, Thauana. Monitoramento e avaliação da política de transferência de renda gaúcha: O programa Rs Mais Igual e a experiência do Observatório De Políticas Sociais Do RS. In: COREZOLA, Fernanda. GRIZA, Aida. RAMOS, Marilia. (Orgs.). Políticas Públicas. Monitoramento, Avaliação, Controle e Participação Social no Governo do Rio Grande do Sul. Porto Alegre: Editora da UFRGS/CEGOV, 2015. 212p.

MIDGLEY, James. Social Development. The Developmental Perspective in Social Welfare. London: Sage, 1995. 
MINAYO, Maria Cecília de S. Construção de indicadores qualitativos para avaliação de mudanças. Revista Brasileira de Educaçáo Médica. v. 1, n. 33, p. 83-91, 2009.

NERI, Marcelo. Mapa de ativos - Combate sustentável à pobreza. Rio de Janeiro: FGV, 2001. - Políticas estruturais de combate à pobreza no Brasil. In: HENRIQUES, R. (Org.). Desigualdade e pobreza no Brasil. Brasília: IPEA, 2003, p. 503-526.

PASE, Hemmerson Luiz; SANTOS, Everton. Capital social e políticas públicas na América Latina. In: BAQUERO, M. (Org.). Cultura(s) política(s) e democracia no século XXI na América Latina. Porto Alegre: UFRGS, 2011, p. 69-9.

PETERS, Guy B. The Politics of Bureaucracy. White Plains: Longman Publishers. 1995.

POCHMANN, Márcio e AMORIN, Ricardo. Atlas da exclusão social no Brasil. São Paulo: Cortez. 2003.

PORTES, Alejandro. Social Capital: its origins and applications in modern sociology. Annu. Rev. Sociol, p. 1-24, 1998.

PUTNAM, Robert. Comunidade e Democracia: a experiência da Itália moderna. Rio de Janeiro: FGV. 1996.

RIO GRANDE DO SUL. Casa Civil. Programa do Governo do Estado auxilia no combate a pobreza. Porto Alegre, 2015. Disponível em: <http://www.rsmaisigual.rs.gov.br/conteudo/1899/?Programa_do_Governo_do_Estado_auxilia_no_ combate_\%C3\%A0_pobreza_extrema>. Acesso em: 21 mar. 2016.

Casa Civil. Falta de Recursos inviabiliza repasses ao RS Mais Igual. Porto Alegre, 2015.

Disponível

em:

<http://www.rsmaisigual.rs.gov.br/conteudo/1927/?Falta_de_recursos_inviabiliza_repasses_ao_RS_

Mais_IguaL>. Acesso em: 22 mar. 2016.

SEN, Amartya. Desenvolvimento como Liberdade. São Paulo: Companhia das Letras, 2010.

Texto recebido em 06 de julho de 2018. Aprovado em 20 de agosto de 2018. 